\title{
1 Barrenia, a new genus associated with roots of switchgrass and pine in
}

\section{2 the oligotrophic pine barrens}

4 Emily WALSH ${ }^{\mathrm{a}}$, Jing $L U O^{\mathrm{a}}$, Abhishek NAIK ${ }^{a}$, Thomas PRETEROTI ${ }^{\mathrm{a}}$, Ning ZHANG ${ }^{\mathrm{a}, \mathrm{b},{ }^{*}}$

$6{ }^{a}$ Department of Plant Biology and Pathology, 201 Foran Hall, 59 Dudley Road, Rutgers

7 University, New Brunswick, New Jersey 08901, USA

$8{ }^{\mathrm{b}}$ Department of Biochemistry and Microbiology, 76 Lipman Drive, Rutgers University,

9 New Brunswick, New Jersey 08901, USA

$10{ }^{*}$ Corresponding author.

11 E-mail address: zhang@aesop.rutgers.edu

12 Tel: 1-848-932-6348, fax: 1-732-932-3844

15 ABSTRACT

16 A new genus Barrenia is described based on multi-gene phylogenetic analyses and

17 phenotypic and ecological characters. Isolated from roots of switchgrass and pitch pine in

18 the acidic and oligotrophic New Jersey Pine Barrens in this study, Barrenia likely has a

19 wide distribution because its internal transcribed spacer (ITS) sequence has high

20 similarity with a number of GenBank sequences from various ecological studies. The

21 majority of these matching samples were from roots of plants in acidic, nutrient-poor

22 environments, as well as from managed sugarcane plantations. Phylogenetic analyses 
23 based on ITS, LSU and RPB1 sequence data strongly support that Barrenia is a

24 monophyletic clade in Helotiales, distinct from any known taxa. Barrenia is

25 phylogenetically close to Acidomelania, Loramyces, Mollisia, and Phialocephala fortinii

26 - Acephala applanata species complex (PAC), the dark septate endophytes. Barrenia can

27 be distinguished from Loramyces and Mollisia by its association with living plant roots.

28 Taxa in PAC also are root endophytes but they have complex phialid arrangements that

29 appear to be lacking in Barrenia. Plant-fungal interaction experiments showed that

30 Barrenia panicia and Acidomelania panicicola significantly promoted root hair growth in

31 switchgrass. Results from this work will facilitate ecological and evolutionary studies on

32 root-associated fungi.

34 Keywords:

35 Dark septate endophytes; Grass; Growth promotion; Leotiomycetes; Phylogeny;

36 Taxonomy

\section{Introduction}

39 Pine barrens is a drought and fire-prone ecosystem with acidic and oligotrophic soils

40 (Forman 1998; Tedrow 1952). The largest pine barrens in the United States is the 1.4

41 million acre $\left(57,000 \mathrm{~km}^{2}\right)$ Pine Barrens of New Jersey, which represents one of a series

42 of barrens along the eastern seaboard of the USA and one of a series of similar

43 ecosystems around the world (Forman 1998). Pines and oaks are the most common trees 
44 in the New Jersey Pine Barrens forests, but the disturbed open areas are dominated by

45 grasses (Poaceae), sedges (Cyperaceae), orchids (Orchidaceae), blueberries and other

46 members of the heath family (Ericaceae). The diversity of fungi and their functions in

47 pine barrens ecosystem remain largely unknown (Dighton et al. 2004; Forman 1998).

48 Dark septate endophytes (DSE) refer to a group of heterogeneous plant root-colonizing

49 ascomycetes that produce melanized, septate hyphae (Jumpponen and Trappe 1998).

50 They have been isolated from over 110 plant families that grow in various environments

51 (Knapp et al. 2012). The best studied DSE are the Phialocephala fortinii- Acephala

52 applanata complex (PAC), a group of asexual fungi in Helotiales of Leotiomycetes

53 (Wang et al. 2006). Fungi in PAC are characterized by darkly pigmented hyphae, and

54 typically produce branched conidiophores, hyaline phialides with collarettes, and

55 intracellular microsclerotia (Grünig et al. 2008a, 2008b; Yu et al. 2001). PAC are the

56 common root associates of many tree species, specifically conifers in forests of the

57 northern hemisphere (Grünig et al. 2008a, 2008b; Menkis 2004; Sieber and Grünig

58 2013). Despite the global pervasiveness of DSE, their ecological roles, phylogenetic

59 relationships and taxonomy remain poorly understood (Knapp et al. 2012; Mandyam and

60 Jumpponen 2005). DSE fungal-plant interaction studies have yielded variable results,

61 likely due to the use of various experimental designs (Grünig et al. 2008b; Newsham

62 2011).

63 In the New Jersey Pine Barrens, we recently uncovered a number of novel fungal

64 lineages from the roots of Poaceae grasses. Two new genera have been described:

65 Pseudophialophora in Magnaporthales of Sordariomycetes (Luo et al. 2014b) and 
66 Acidomelania, a novel DSE close to PAC in Leotiomycetes (Walsh et al. 2014). In this

67 study we propose another new genus Barrenia from apparently healthy switchgrass and

68 pitch pine roots in New Jersey Pine Barrens. Barrenia belongs in Helotiales of

69 Leotiomycetes and can be distinguished from PAC and other allied fungi based on

70 phylogenetic analyses, as well as ecology and morphology. We also conducted a plant-

71 fungal interaction experiment for Barrenia and Acidomelania species with switchgrass,

72 in order to understand their roles in the ecosystem.

\section{$73 \quad 2$ Materials and methods}

$74 \quad 2.1$ Fungal isolation

75 Poaceae grass roots were collected from three locations (N 40 12.00, W 74 30.00; N40

76 04.084, W74 26.696; and N 39 46.136, W 74 40.885) in New Jersey Pine Barrens in 2012

77 and 2013. Native pitch pine (Pinus rigida) roots were collected from two locations (N40

78 04.084, W74 26.696; and N 39 46.136, W 74 40.885) in New Jersey Pine Barrens in

79 2014. Soil $\mathrm{pH}$ of the sampling locations ranged from 4.7 to 5.2. Root samples were rinsed

80 thoroughly to remove soil from the surface, cut into $10-20 \mathrm{~mm}$ pieces then surface

81 disinfected with sequential washes of $95 \%$ ethanol for $30 \mathrm{~s}, 0.5 \% \mathrm{NaOCl}$ for $2 \mathrm{~min}$ and

$8270 \%$ ethanol for $2 \mathrm{~min}$. After several rinses with sterile water and drying, the root

83 samples were cut into $5 \mathrm{~mm}$ pieces and plated on acidified malt extract agar (AMEA, 1.5

$84 \mathrm{ml} 85 \%$ lactic acid per liter of $2 \%$ malt extract agar). Plates were incubated at room

85 temperature with $12 \mathrm{~h} \mathrm{light} \mathrm{and} 12 \mathrm{~h}$ dark cycles. Fungal cultures were transferred to

86 fresh AMEA and purified by sub-culturing from emergent hyphal tips.

87 
90 Fungal isolates were grown on cellophane overlaid 2\% MEA (BD Difco, Maryland) and

$912 \%$ water agar (WA). Cultures were incubated at $20 \mathrm{C}$ in the dark with three replicates.

92 Colony diameter was measured after 20 days. The color names of colonies followed

93 Ridgway (1912). The following media also were used to induce sporulation: Cornmeal

94 Agar (CMA, BD Difco, Maryland), Oatmeal Agar (OA, BD Difco, Maryland), Potato

95 Dextrose Agar (PDA, BD Difco, Maryland), Filtered Ground Pine Needle Agar (FGPNA,

96 Luchi et al. 2007), Synthetic Nutrient Agar (SNA, Gams et al. 1998), WA amended with

97 autoclaved switchgrass leaves, WA amended with autoclaved switchgrass roots, WA

98 amended with autoclaved pine needles, and WA amended with autoclaved pine roots.

99 Cultures were incubated at $20 \mathrm{C}$ and $25 \mathrm{C}$ in the dark with three replicates. Colonies were

100 checked weekly for 10 months.

$101 \quad 2.3$ DNA extraction, amplification and sequencing

102 Genomic DNA was extracted from fungal mycelium using the UltraClean Soil DNA

103 isolation kit (MoBio, California) following the manufacturer's instructions. PCR was

104 performed with Taq 2X Master Mix (New England BioLabs, Maine), following the

105 manufacturer's instructions. PCR cycling conditions for the internal transcribed spacer

106 (ITS) and the large subunit of ribosomal RNA genes (LSU) consisted of an initial

107 denaturation step at $95 \mathrm{C}$ for $2 \mathrm{~min}, 35$ cycles of $95 \mathrm{C}$ for $45 \mathrm{~s}, 54 \mathrm{C}$ for $45 \mathrm{~s}, 72 \mathrm{C}$ for 1.5

$108 \mathrm{~min}$, and a final extension at $72 \mathrm{C}$ for $5 \mathrm{~min}$. For the largest subunit of RNA polymerase

109 II (RPB1) the cycling conditions included an initial denaturation step at $95 \mathrm{C}$ for 2 min,

11035 cycles of $95 \mathrm{C}$ for $60 \mathrm{~s}, 55 \mathrm{C}$ for $1.5 \mathrm{~min}, 72 \mathrm{C}$ for $2 \mathrm{~min}$, and a final extension at $72 \mathrm{C}$ 
111 for $10 \mathrm{~min}$. Primers used in this study are as follows: ITS1 and ITS4 for the ITS region

112 (White et al. 1990), ITS1 and LR5 for the LSU locus (Rehner and Samuels 1995), and

113 RPB1 Af (Hall and Stiller 1997) and RPB1 CrRev (Matheny et al. 2002) for the RPB1

114 gene. PCR products were purified with ExoSAP-IT (Affymetrix, California) and

115 sequenced with the PCR primers by Genscript Inc. (Piscataway, New Jersey).

\subsection{Sequence alignment and phylogenetic analyses}

117 Six representative isolates of the new taxon (CM11m2, CM14P64, AL5m2, WSF1R37,

118 WSF14P13, and WSF14P22) as well as other reference Leotiomycetes species (Table 1)

119 were included in the phylogenetic analyses. The ITS dataset included sequences of the six

120 new isolates from this study and 15 reference sequences of Helotiales. The LSU dataset

121 included the six new sequences and 28 reference sequences of Helotiales and

122 Rhytismatales. The three-gene (ITS, LSU and RPB1) alignment included the six new

123 sequences and 12 reference sequences of Helotiales. Sequences were aligned with

124 MUSCLE (Edgar 2004). Genealogical concordance was evaluated with the

125 nonparametric Templeton Wilcoxon signed-rank test in PAUP*4.0b10 (Swofford 2002),

126 with $95 \%$ bootstrap consensus trees as constraints. No significant conflict was found

127 among the trees based on the individual and combined three-gene datasets. Maximum

128 likelihood (ML) tree was generated with MEGA 6 (Tamura et al. 2013). Models with the

129 lowest BIC scores (Bayesian Information Criterion) were considered to describe the

130 substitution pattern the best. The best models for LSU, ITS and three-gene datasets were

131 Tamura-3 parameter, Kimura 2-parameter, Kimura 2-parameter, respectively. Initial

132 tree(s) for the heuristic search were obtained automatically by applying Neighbor-Joining

133 and BioNJ algorithms to a matrix of pairwise distances estimated using the Maximum 
134 Composite Likelihood approach, and then selecting the topology with superior log

135 likelihood value. A discrete Gamma distribution was used to model evolutionary rate

136 differences among sites. Bootstrap was computed for 500 replications. All positions

137 containing gaps and missing data were excluded from the analyses. Maximum likelihood

138 analysis using RAxML generated the same tree topologies as those produced by MEGA.

1402.5 Plant- fungal interaction experiment

141 Fungal isolates WSF1R37, WSF14P22, and A. panicicola isolate 61R8 were used in the

142 seedling inoculation experiment. Switchgrass ('Kanlow') seeds were surface disinfected

143 as follows: $95 \%$ ethanol for $30 \mathrm{~s}, 0.5 \% \mathrm{NaOCl}$ for $1 \mathrm{~min}, 70 \%$ ethanol for $1 \mathrm{~min}$, rinsed

144 with sterile distilled $\mathrm{H}_{2} \mathrm{O}$ and allowed to germinate in the dark at $25 \mathrm{C}$ for 3 days. Agargel

145 (Sigma-Aldrich, USA) plates were made following manufacturer's instructions, and were

146 cut in half, with one side removed. On the cut surface of an Agargel plate, three $10 \mathrm{~mm} \times$

$14710 \mathrm{~mm} \times 5 \mathrm{~mm}$ plugs from a one-week old fungal culture grown on MEA were placed

148 equidistance from one another. Germinated switchgrass seeds with visible radicle were

149 then placed on the plugs. Sterile MEA plugs were used as negative control. Cultures were

150 incubated at $25 \mathrm{C}$ under $12 \mathrm{hr}$ light and dark cycle with nine replicates. Root length was

151 measured 7 days after inoculation.

152

\section{$153 \quad 3$ Results}

1543.1 Culture morphology and growth rate

155 Isolate WSF1R37 produced dense Cinnamon Brown mycelium on MEA, and Ochraceous

156 Tawny mycelium on WA. Colony diameter measurements for isolate WSF1R37 after 20 
157 days were $75 \mathrm{~mm}$ on average on MEA with standard deviation (SD) of 2.6, and $47 \mathrm{~mm}$

158 on average on WA with SD of 2.6. Isolate WSF14P22 produced dense Cinnamon Brown

159 mycelium on MEA, and Buckthorn Brown mycelium on WA. Colony diameter

160 measurements for isolate WSF14P22 after 20 days were $28 \mathrm{~mm}$ on average on MEA with

161 SD of 0.6 , and $26 \mathrm{~mm}$ on average on WA with SD of 1.0. Despite using a wide variety of

162 media, sporulation has been observed only for isolate WSF14P22.

163

$164 \quad 3.2$ Sequence data and phylogeny

165

166 There were 1246 characters in the LSU alignment, 573 in ITS, 489 in RPB1 and 2308 in

167 the three-gene alignment (TreeBASE study number 18173). Maximum likelihood trees

168 based on LSU, ITS and three gene sequences are shown in Figs 1-3. All three

169 phylogenies supported that the new isolates formed a clade in Helotiales separated from

170 any known taxa. The LSU tree indicated that they were close to Acidomelania panicicola,

171 Loramyces macrosporus, Mollisia cinerea and PAC. The ITS tree showed that these new

172 isolates were closely related to A. panicicola, M. cinerea, Phialocephala scopiformis and

173 L. macrosporus. In the ITS tree, isolates WSF1R37, AL5m2, and CM11m2 formed a

174 well-supported group, while isolates WSF14P22, WSF14P13, and CM14P64 formed

175 another. The two groups were also recognized and supported by the LSU and RPB1 trees,

176 and variation in the phylogenetic relationships of these isolates only occurred within

177 these respective groupings. Based on the molecular phylogenetic analyses, morphological

178 characters and their ecological features, a new genus and two new species are proposed. 
181

182 Barrenia E. Walsh \& N. Zhang, gen. nov.

$$
\text { MycoBank: MB811715 }
$$
Etymology: "Barren" refers to the pine barrens ecosystem where the fungi were

185 discovered. Morphological description: Colonies on MEA darkly pigmented, surface fluffy, 187 aerial hyphae thick and light brown. Colonies on WA light brown, sparse aerial hyphae. 188 Sporulation observed in only one species. Molecular description: Barrenia differs from other closely related taxa by the

190 following fixed nucleotides in the largest subunit of RNA polymerase II gene (RPB1)

191 from the 3-gene alignment: positions 2055 (T), 2081 (G), 2083 (C), and 2099 (G). (Fig 4)

192 Type species: Barrenia taeda

193 Habitat: Endophytic in roots of pine.

$194 \quad$ Known distribution: New Jersey Pine Barrens, United States. Morphological description: Colonies on MEA $55 \mathrm{~mm}$ diam after $20 \mathrm{~d}$ in the dark

200 at $25 \mathrm{C}$, Cinnamon Brown, surface fluffy, aerial hyphae thick and light brown, reverse 201 pigmented, Warm Sepia. Colonies on WA reaching $51 \mathrm{~mm}$ diam after $20 \mathrm{~d}$ in the dark at 20225 C, Ochraceous Tawny, aerial hyphae sparse, reverse pigmented, Cinnamon Brown. 
203 Warm Sepia, paddle-shaped hyphopodium-like structures formed in inoculated 204 switchgrass root tissue.

205 Molecular description: Barrenia panicia differs from Barrenia taeda by the 206 following fixed nucleotides of the largest subunit of RNA polymerase II gene (RPB1)

207 from the 3-gene alignment: positions $2057(\mathrm{G}), 2069$ (C), $2096(\mathrm{~T}), 2097(\mathrm{~T})$, and 2120 208 (A). (Fig 4) Holotype: United States: New Jersey: Wharton State Forest, N 39 45.346, W 074

$21041.684,3 \mathrm{~m}$ alt., from roots of Panicum virgatum, 5 Jun. 2013, E. Walsh \& N. Zhang, 211 WSF1R37 (RUTPP-WSF1R37).

212 Other materials examined: United States: New Jersey: Assunpink Lake, N 40 213 12.00, W 74 30.00, 3 m alt., from roots of Digitaria sp., 30 Aug. 2012, E. Walsh \& N. 214 Zhang AL5m2; Colliers Mills, N40 04.084 W74 26.696, 5 m alt., from roots of Coix 215 lacryma - jobi, 30 Aug. 2012, E. Walsh \& N. Zhang CM11m2.

217 Barrenia taeda E. Walsh \& N. Zhang, sp. nov. (Fig 6A-D)

$218 \quad$ MycoBank: MB811717

219 Etymology: "taeda" means pine wood and refers to the host.

220 Morphological description: Colonies on MEA $28 \mathrm{~mm}$ diam after $20 \mathrm{~d}$ in the dark

221 at $25 \mathrm{C}$, Cinnamon Brown, surface fluffy, aerial hyphae thick and light brown, reverse

222 pigmented, Mummy Brown. Colonies on WA reaching $31 \mathrm{~mm}$ diam after $20 \mathrm{~d}$ in the dark

223 at $25 \mathrm{C}$, Buckthorn Brown, sparse aerial hyphae, reverse pigmented, Buckthorn Brown.

224 Conidia formed on WA with autoclaved switchgrass leaves after 10 months at 20-25 C in 225 dark or light. Conidiophores simple, hyaline, and straight. Conidiogenous cells 
226 cylindrical, $27.25-43.68 \times 0.89-1.94 \mathrm{um}(\mathrm{n}=20)$, tapered at the top $0.53-1.16 \mathrm{um}$, and 227 wider at the base, $1.47-2.46 \mathrm{um}(\mathrm{n}=20)$. Conidia aggregated in slimy heads, fusiform, 228 aseptate, hyaline, smooth, $1.92-4.04 \times 0.7-1.67 \mathrm{um}(\mathrm{n}=50)$.

229 Molecular description: Barrenia taeda differs from Barrenia panicia by the 230 following fixed nucleotides in the largest subunit of RNA polymerase II gene (RPB1) 231 from the 3-gene alignment: positions 2057 (A), 2069 (A), 2096 (C), 2097 (C), and 2120 232 (T). (Fig 4)

233 Holotype: United States: New Jersey: Wharton State Forest N 39 45.346, W 074 234 41.684, 3 m alt., from roots of Pinus rigida, 26 Jun. 2014, E. Walsh \& N. Zhang 235 WSF14P22 (RUTPP-WSF14P22).

236 Other materials examined: United States: New Jersey: Wharton State Forest, N 23739 45.346, W 074 41.684, 3 m alt., from roots of Pinus rigida, 26 Jun. 2014, E. Walsh \& 238 N. Zhang WSF14P13; Colliers Mills, N40 04.084 W74 26.696, 5 m alt., from roots of 239 Pinus rigida, 4 Jun. 2014, E. Walsh \& N. Zhang CM14P64.

241 Notes:

242 Barrenia differs from Loramyces and Mollisia by its association with living plant roots 243 because Loramyces and Mollisia species are associated with dead or decaying above244 ground plant parts (Digby and Goos 1987; Ingold and Chapman 1952; Weston 1929). 245 Taxa in the PAC are also root endophytes, but they exhibit complex phialid arrangements 246 that appear to be lacking in Barrenia. Moreover, Barrenia has 93\% or less ITS sequence 247 similarities to the above-mentioned close relatives or any other described species with 248 accessible ITS sequences. The two Barrenia species differ from each other on host and 
249 growth rate. The pine associated B. taeda exhibited slower growth than the grass

250 associated B. panicia on both WA and MEA. There is a $96 \%$ similarity in ITS sequences

251 between B. panicia and B. taeda.

252

253 3.4 Plant-fungal interaction experiment

254 Switchgrass seedlings inoculated with A. panicicola isolate $61 \mathrm{R} 8$ and B. panicia

255 WSF1R37 produced dense root hairs all the way to the root apical meristem area, whilst

256 the control seedlings only produced dense root hairs at the region of maturation of the

257 root (Fig 7). In addition, the roots inoculated with A. panicicola isolate $61 \mathrm{R} 8$ and B.

258 panicia WSF1R37 had a serpentine growth pattern, whilst the control roots were straight.

259 Hyphopodia-like strutures were observed on the switchgrass seedling roots inoculated

260 with B. panicia WSF1R37 (Fig 5). Root length for seedlings inoculated with B. panicia

261 WSF1R37 after 7 days were $17.4 \mathrm{~mm}$ on average with SD of 1.8 , not significantly

262 different from the control, which was $19 \mathrm{~mm}$ on average with SD of 5.1. Seedlings

263 inoculated with B. taeda WSF14P22 showed no difference in root hair production with

264 the control. Root length for those inoculated with B. taeda WSF14P22 after 7 days was

$2658.1 \mathrm{~mm}$ on average with SD of 1.6, which was significantly shorter than the control (Fig $2667)$.

2684 Discussion

269 Our recent survey on fungi associated with grass roots uncovered a number of novel DSE

270 in Leotiomycetes from the pine barrens ecosystem (Luo et al. 2014a, 2014b; Walsh et al.

271 2014). Leotiomycetes are morphologically and ecologically diverse and the phylogenetic 
272 relationships within this class are not well resolved due to lack of molecular data (Wang

273 et al. 2006). Based on the multi-locus phylogenetic analyses, the new genus Barrenia

274 proposed here belongs to Helotiales, which encompasses plant pathogens, saprobes and

275 endophytes. The dark, septate hyphal morphology of Barrenia spp., their root-colonizing

276 habit and phylogenetic closeness to PAC indicate that they likely are also DSE.

277 The best studied DSE is the PAC, specifically P. fortinii. However, the ecological

278 functions of PAC and other DSE remain elusive. Host-fungal interaction experiments

279 often yielded inconsistent results under various experimental conditions in different

280 laboratories (Mandyam and Jumpponen 2005). This prompted us to examine the

281 interaction between B. panicia, B. taeda, A. panicicola and switchgrass, which is the host

282 of B. panicia and A. panicicola. Our inoculation results indicated that A. panicicola and

283 B. panicia remarkably promoted the root hair growth in switchgrass. In switchgrass roots,

284 B. panicia produced hyphopodium-like structures, which may perform penetration and

285 nutrient exchange function between the fungus and the host plant (Delaux et al. 2013;

286 Walker 1980). Barrenia taeda, originally isolated from pine roots, had a negative effect

287 on root elongation in switchgrass seedlings. These results corroborate Mandyam et al.

288 (2010; 2012) that although DSE fungi have a broad host range, their effects and

289 characteristics can be considered host specific. Further studies are needed to understand

290 the molecular mechanisms of the observed different interactions between these DSE and

291 plants.

292 The phylogenetic analysis in this study indicated that Barrenia is close to Acidomelania,

293 Loramyces, Mollisia, and PAC. The phylogenetic proximity of Mollisia, Loramyces and 
294 PAC was also supported by Zijlstra et al. (2005) and Wang et al. (2006). Barrenia can be

295 distinguished from Loramyces and Mollisia by its association with living plant roots.

296 Although taxa in PAC are also root endophytes, morphologically they can be

297 distinguished from Barrenia. In addition, Barrenia has 93\% or less ITS sequence

298 similarities to the above-mentioned close relatives or any other described species with

299 accessible ITS sequences. The family placement of Barrenia is not determined here

300 because the Leotiomycetes phylogeny is poorly resolved and several families in this class

301 likely are polyphyletic (Wang et al. 2006).

302 The six Barrenia isolates from New Jersey Pine Barrens were grouped into two well-

303 supported clades. We delimited the two species based on the ITS, LSU and 3-gene trees.

304 The BLAST results in GenBank indicated that Barrenia might have a wide distribution.

305 Sixteen ITS sequences in GenBank had 97-99\% identities with that of B. panicia isolate

306 WSF1R37, for example, GU973749 from sugarcane root in Brazil, HQ889709 from

307 Cymbidium insigne root in China, and AY599235 from grass root in The Netherlands.

308 Twelve ITS sequences in GenBank had 97-99\% identities with that of B. taeda isolate

309 WSF14P22, for example, JQ272328 from Rhododendron root in USA and KJ817299

310 from Vaccinium vitis-idaea in Inner Mongolia. The host plants of the matched sequences

311 in GenBank are largely Ericaceae, terrestrial orchids, grasses and conifers, usually found

312 in acidic and infertile soils (Keddy 2007). This distribution pattern was also found in

313 Acidomelania panicicola, the other root associated fungus frequently isolated from the

314 pine barrens (Walsh et al. 2014). The plant root hair growth promotion effect of $A$.

315 panicicola and B. panicia discovered in this study coupled with their distribution pattern

316 suggest that these species may play a role in plant adaptation to acid, low nutrient soils. 
317 In this study we named a new genus and two species of root-colonizing fungi associated

318 with plants living in acidic, nutrient poor environment. The phylogenetic and taxonomic

319 work and the plant-fungal interaction results reported here will aid future ecological and

320 evolutionary studies on root-associated fungi.

\section{Acknowledgments}

323 The research was financially supported by the National Science Foundation of the United

324 States (grant numbers DEB 1145174 and DEB 1452971) to Ning Zhang.

325

326 Figure Legends:

327

328 Fig 1 - Maximum likelihood phylogenetic tree inferred from the large subunit of rRNA

329 gene sequence. Bootstraps higher than 70 have thickened branches.

330

331 Fig 2 - Maximum likelihood phylogenetic tree inferred from the internal transcribed 332 spacer sequences of rRNA gene. Bootstraps higher than 70 have thickened branches.

334 Fig 3 - Maximum likelihood phylogenetic tree inferred from combined ITS, LSU, and $335 R P B 1$ gene sequence datasets. Bootstraps higher than 70 have thickened branches.

337 Fig 4 - Partial RPB1 gene alignment of Barrenia panicia (WSF1R37), B. taeda

338 (WSF 14P22), and closely related members of Leotiomycetes: Acidomelania panicicola, 339 Mollisia cinerea and Lachnum virgineum. Black highlights indicate differences between 
340 the genus Barrenia and related Leotiomycetes, while gray highlights indicate differences

341 between B. panicia and B. taeda.

342

343 Fig 5 - Morphological characters of Barrenia panicia holotype isolate WSF1R37. A-C.

344 Pseudohyphopodia on inoculated switchgrass seedling roots. Bar $=10 \mu \mathrm{m}$

345

346 Fig 6 - Morphological characters of Barrenia taeda holotype isolate WSF14P22. A-D

347 Conidia and conidiogenious cells. Bar $=10 \mu \mathrm{m}$

348

349 Fig 7 - Switchgrass seedling two days after inoculation with A. Acidomelania panicicola

350 holotype isolate 61 R8 B. Control; three days after inoculation with C. Barrenia panicia

351 holotype isolate WSF1R37, D. Control, E. Barrenia taeda holotype isolate WSF14P22.

$352 \quad$ Bar $=1 \mathrm{~mm}$

353

354

355

356

357 REFERENCES

358 Delaux PM, Sejalon-Delmas N, Becard G, Ane JM, 2013. Evolution of the plant-microbe 359 symbiotic 'toolkit'. Trends in Plant Science 18:298-304.

360 Digby S, Goos R, 1987. Morphology, development and taxonomy of Loramyces.

$361 \quad$ Mycologia 79:821-831 
362 Dighton J, Tuininga AR, Gray DM, Huskins RE, Belton T, 2004. Impacts of atmospheric

363 deposition on New Jersey pine barrens forest soils and communities of

364 ectomycorrhizae. Forest Ecology and Management 201:131-144.

365 Edgar RC, 2004. MUSCLE: multiple sequence alignment with high accuracy and high

366 throughput. Nucleic Acids Research 32:1792-1797.

367 Forman RT, 1998. Pine Barrens: Ecosystem and Landscape. Rutgers University Press, 368 New Jersey.

369 Gams W, Hoekstra ES, Aptroot A, 1998. CBS course of mycology. $4^{\text {th }}$ ed. Baarn, $370 \quad$ Netherlands : Centraalbureau voor Schimmecultures.

371 Grünig CR, Duo A, Sieber T, Holdenrieder O, 2008a. Assignment of species rank to six reproductively isolated cryptic species of the Phialocephala fortinii s.1.-Acephala applanata species complex. Mycologia 100:47-67.

374 Grünig CR, Queloz V, Sieber TN, Holdenrieder O, 2008b. Dark septate endophytes 375 (DSE) of the Phialocephala fortinii s.1. -Acephala applanata species complex in 376 tree roots: classification, population biology, and ecology. Botany 86:1355-1369. 377 Hall BD, Stiller JW, 1997. The origin of red algae: Implications for plastid evolution. Proceedings of the National Academy of Sciences of the USA 94:4520-4525.

379 Ingold CT, Chapman B, 1952. Aquatic Ascomycetes: Loramyces juncicola Weston and 380 L. macrospora n. sp. Transactions of the British Mycological Society 35:268-272

381 Jumpponen A, Trappe JM. 1998. Dark septate endophytes: a review of facultative 382 biotrophic root-colonizing fungi. New Phytol 140:295-310.

383 Keddy PA, 2007. Plants And Vegetation: Origins, Processes, Consequences. Cambridge $384 \quad$ University Press, UK. 
385 Knapp DG, Pintye A, Kovacs GM, 2012. The dark side is not fastidious--dark septate 386 endophytic fungi of native and invasive plants of semiarid sandy areas. PLoS 387 ONE 7:e32570.

388 Luchi N, Capretti P, Bonello P, 2007. Production of Diplodia scrobiculata and Diplodia 389 pinea pycnidia on ground Austrian pine needle agar medium. Phytopathologia $390 \quad$ Mediterranea 46:230-235.

391 Luo J, Walsh E, Naik A, Zhuang W, Zhang K, Cai L, Zhang N, 2014a. Temperate pine 392 barrens and tropical rain forests are both rich in undescribed fungi. PLOS ONE $393 \quad 9: \mathrm{e} 103753$.

394 Luo J, Walsh E, Zhang N, 2014b. Four new species in Magnaporthaceae from grass roots 395 in New Jersey Pine Barrens. Mycologia 106: 580-588.

396 Mandyam K, Fox C, Jumpponen A, 2012. Septate endophyte colonization and host 397 responses of grasses and forbs native to a tallgrass prairie. Mycorrhiza 22:109$398 \quad 119$.

399 Mandyam K, Jumpponen A, 2005. Seeking the elusive function of the root-colonising $400 \quad$ dark septate endophytic fungi. Studies in Mycology 53:173-189.

401 Mandyam K, Loughin T, Jumpponen A, 2010. Isolation and morphological and 402 metabolic characterization of common endophytes in annually burned tallgrass 403 prairie. Mycologia 102:813-821.

404 Matheny PL, Liu YJ, Ammirati JF, Hall, BD, 2002. Using Rpb1 Sequences To Improve 405 Phylogenetic Inference Among Mushrooms (Inocybe, Agaricales). American $406 \quad$ Journal of Botany 89:688-698. 
407 Menkis A, Allmer J, Vasiliauskas R, Lygis V, Stenlid J, Finlay R, 2004. Ecology and 408 molecular characterization of dark septate fungi from roots, living stems, coarse $409 \quad$ and fine woody debris. Mycological Research 108:965-973.

410 Newsham KK. 2011. A meta-analysis of plant responses to dark septate root endophytes. $411 \quad$ New Phytol 190:783-793.

412 Otgonsuren B, Lee MJ, 2013. Ectomycorrhiza Enhanced the Cold-Acclimation Growth 413 and Freeze Tolerance of Scots Pine (Pinus sylvestris L.). Taiwan Journal of $414 \quad$ Forest Science 28:97-111.

415 Rehner SA, Samuels GJ, 1995. "Molecular systematics of the Hypocreales - a

416 teleomorph gene phylogeny and the status of their anamorphs." Canadian Journal $417 \quad$ of Botany 73:S816-S823.

418 Ridgway R, 1912. Color standards and color nomenclature. The author, Washington DC.

419 Sieber TN, Grünig CR, 2013. Fungal root endophytes, in: Eshel A, Beeckman T (Eds),

420 Plant Roots - The Hidden Half, 4th ed. CRC Press, Taylor \& Francis Group, Boca $421 \quad$ Raton, FL, USA.

422 Swofford DL, 2002. PAUP* 4.0b10: phylogenetic analysis using parsimony (*and other 423 methods). Sunderland, Massachusetts: Sinauer Associates

424 Tamura K, Stecher G, Peterson D, Filipski A, Kumar S, 2013. MEGA6: Molecular 425 Evolutionary Genetics Analysis version 6.0. Molecular Biology and Evolution $426 \quad 30: 2725-2729$.

427 Taylor JW, Jacobson DJ, Kroken S, Kasuga T, Geiser DM, Hibbett DS, Fisher MC, 2000. 428 Phylogenetic species recognition and species concepts in fungi. Fungal Genetics $429 \quad$ and Biology 31:21-32. 
430 Tedrow JCF, 1952. Soil Conditions in the Pine Barrens of New Jersey. Bartonia 26: 28$431 \quad 35$.

432 Walker J, 1980. Gaeumannomyces, Linocarpon, Ophiobolus and several other genera of 433 scolecospored ascomycetes and Phialophora conidial states, with a note on $434 \quad$ hyphopodia. Mycotaxon 11:1-129.

435 Walsh E, Luo J, Zhang N, 2014. Acidomelania panicicola gen. et sp. nov. from 436 switchgrass roots in acidic New Jersey pine barrens. Mycologia 106:856-864.

437 Wang Z, Johnston PR, Takamatsu S, Spatafora JW, Hibbett DS, 2006. Toward a 438 phylogenetic classification of the Leotiomycetes based on rDNA data. Mycologia 98:1065-1075.

440 Weston WH, 1929. Observations on Loramyces, an undescribed aquatic ascomycete. $441 \quad$ Mycologia 21:55-76.

442 White TJ, Bruns T, Lee S, Taylor J, 1990. Amplification and direct sequencing of fungal

443 ribosomal RNA genes for phylogenetics. In: Innis M, Gelfand D, Sninsky J, 444 White T (eds) PCR Protocols: A Guide to Methods and Applications. New York: $445 \quad$ Academic Press.

446 Yu T, Nassuth A, Peterson RL, 2001. Characterization of the interaction between the 447 dark septate fungus Phialocephala fortinii and Asparagus officinalis roots. $448 \quad$ Canadian Journal of Microbiology 47:741-753.

449 Zijlstra J, Van'tHof P, Baar J, Verkley G, Summerbell R, Paradi I, Braakhekke W, 450 Berendse F, 2005. Diversity of symbiotic root endophytes of the Helotiales in 451 ericaceous plants and the grass, Dechampsia flexuosa. Studies in Mycology $452 \quad \mathbf{5 3}: 147-162$. 
453

454 


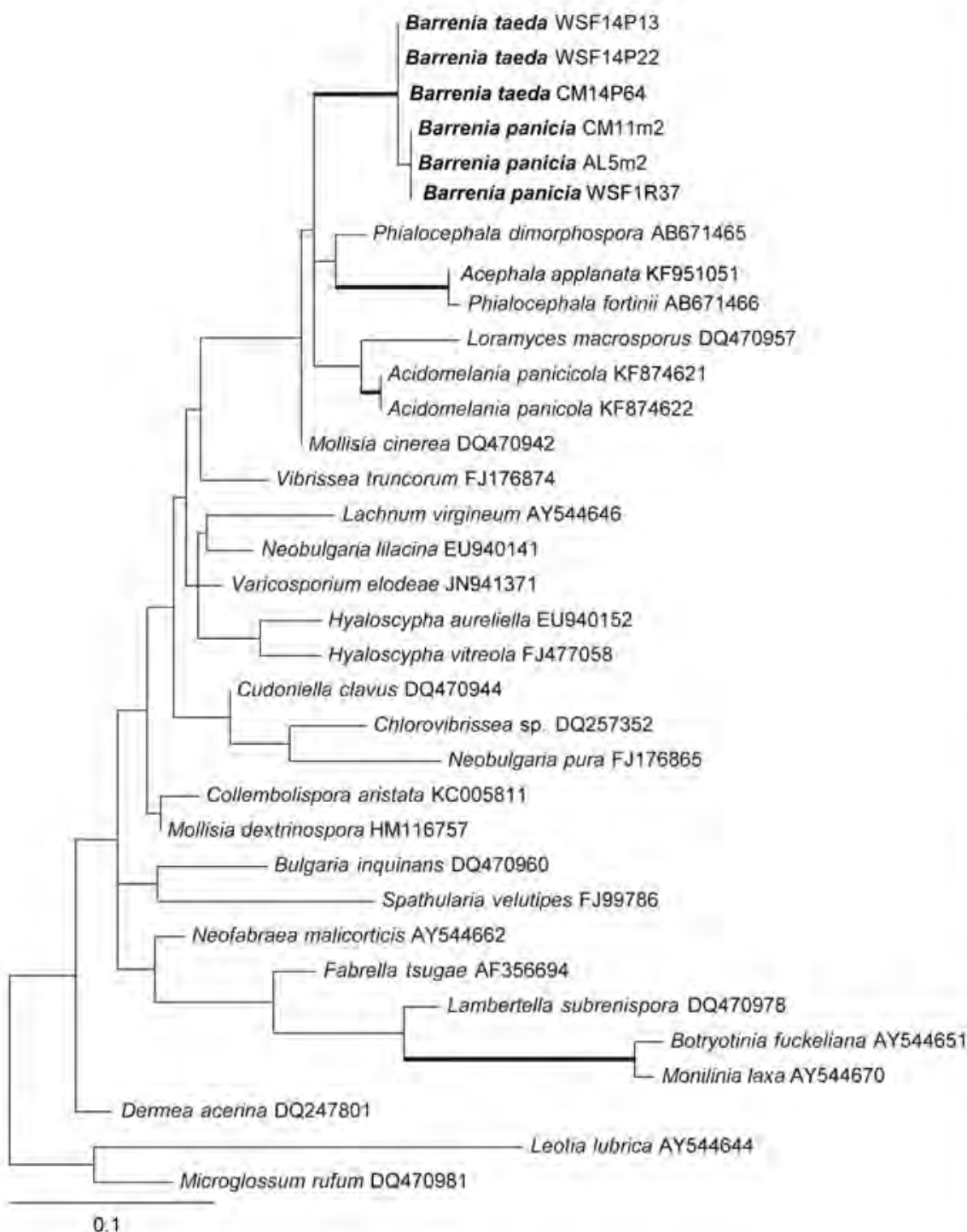

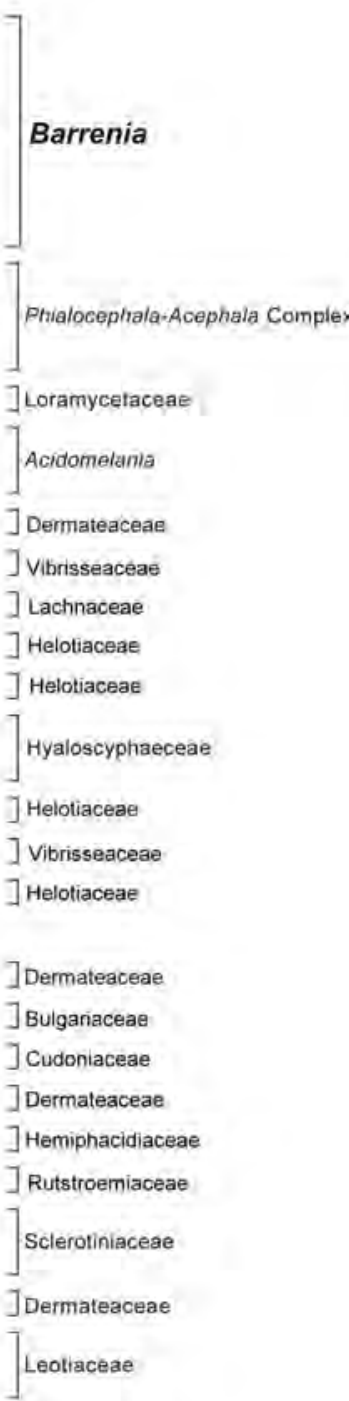


Figure 2

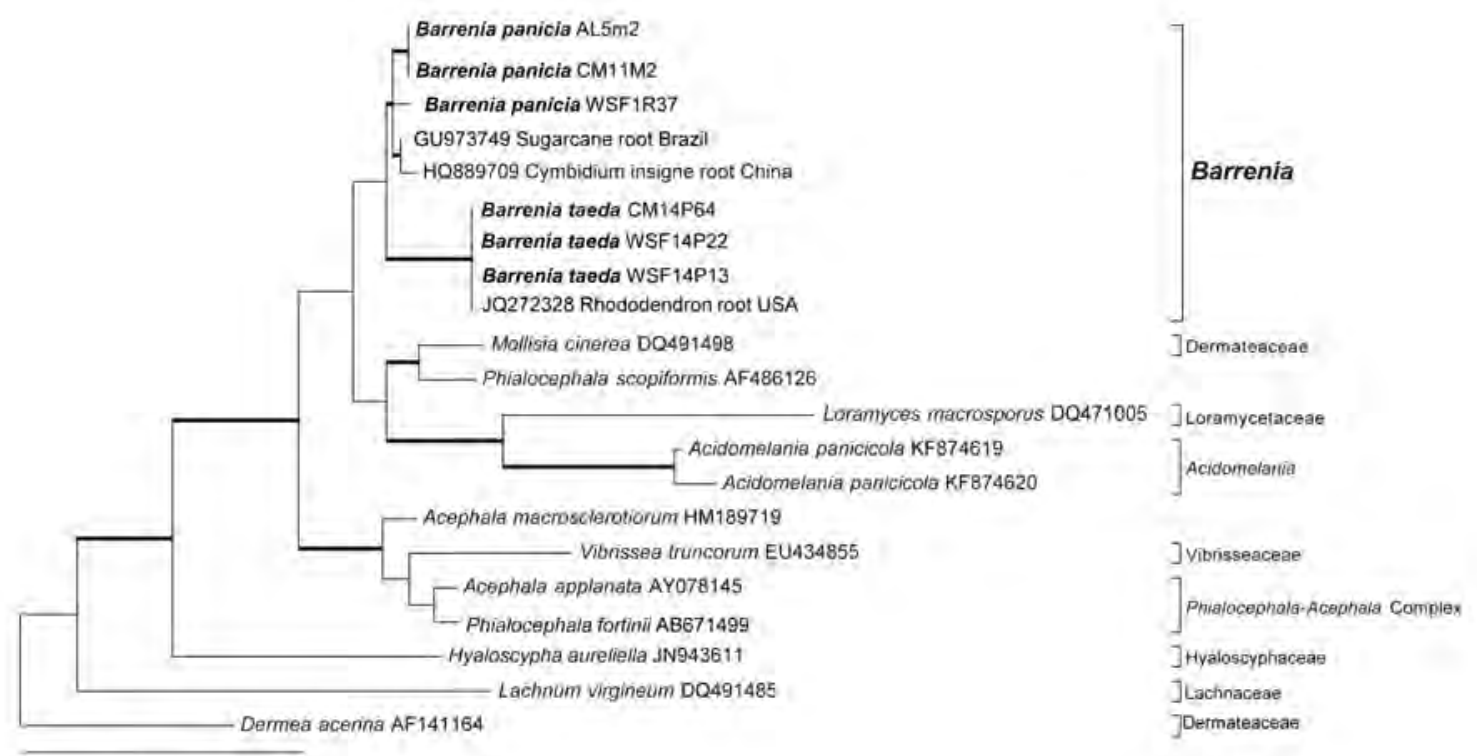



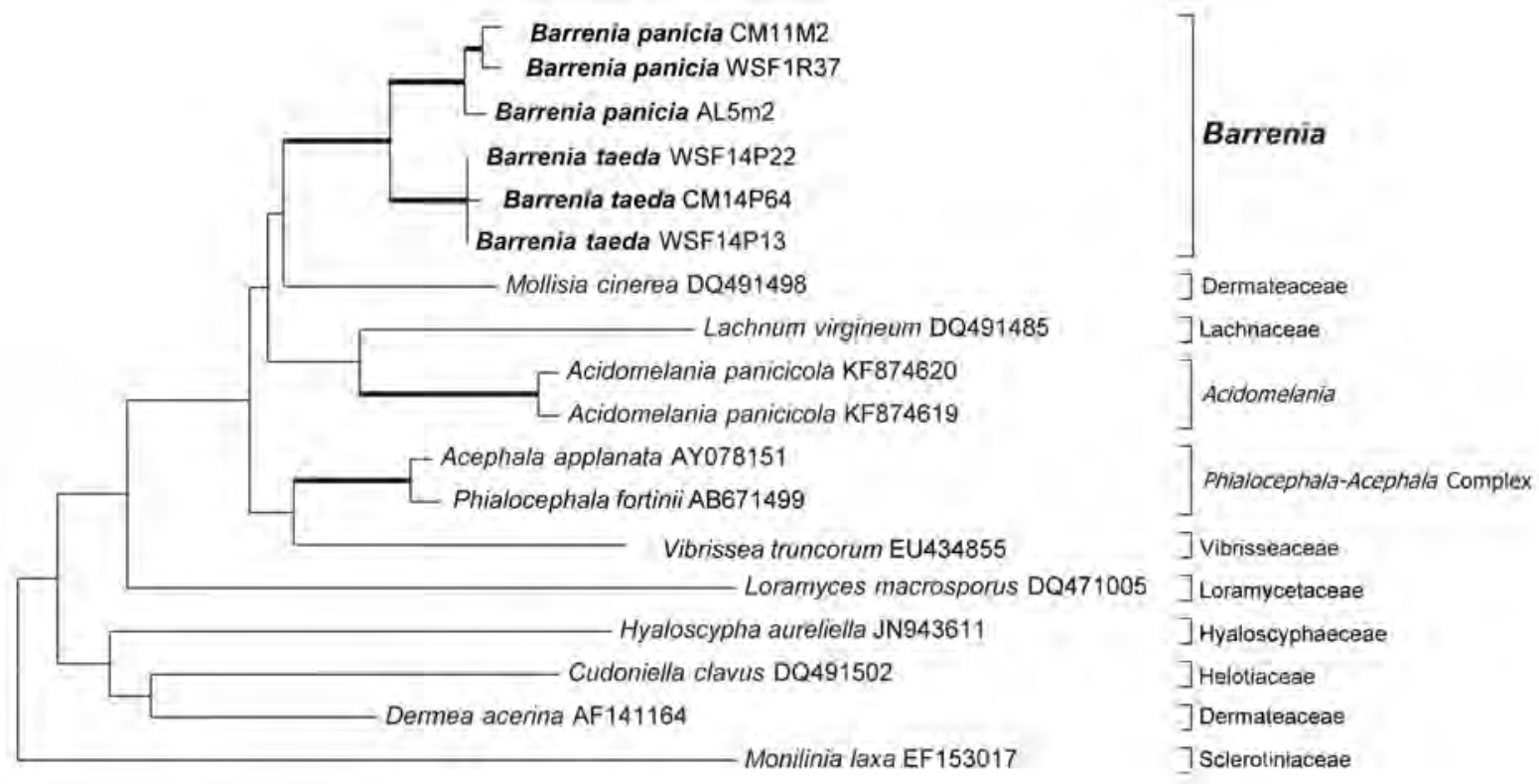

0.1 


\begin{tabular}{|c|c|}
\hline arrenia panicia & 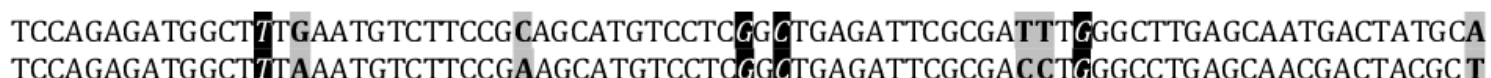 \\
\hline & TCCAGAGATGGCTTTAAATGTCTTCCGAAGCATGTCCTGGGCTGAGATTCGCGACCTGGGCCTGAGCAACGACTAC \\
\hline panicicola & TCTCAATGTCTTCCGGTCCATGTCT \\
\hline & GTCTTCA \\
\hline & ¿CCTGAGCAATGATTAT \\
\hline
\end{tabular}


Figure 5

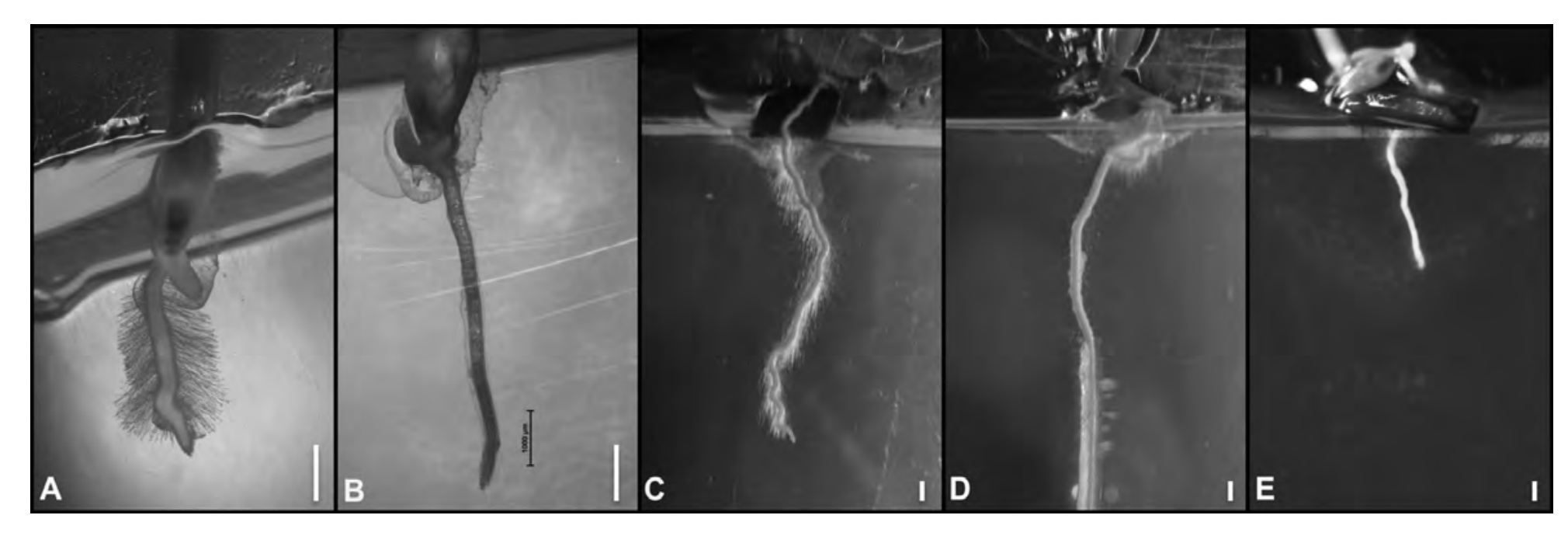


Figure 6

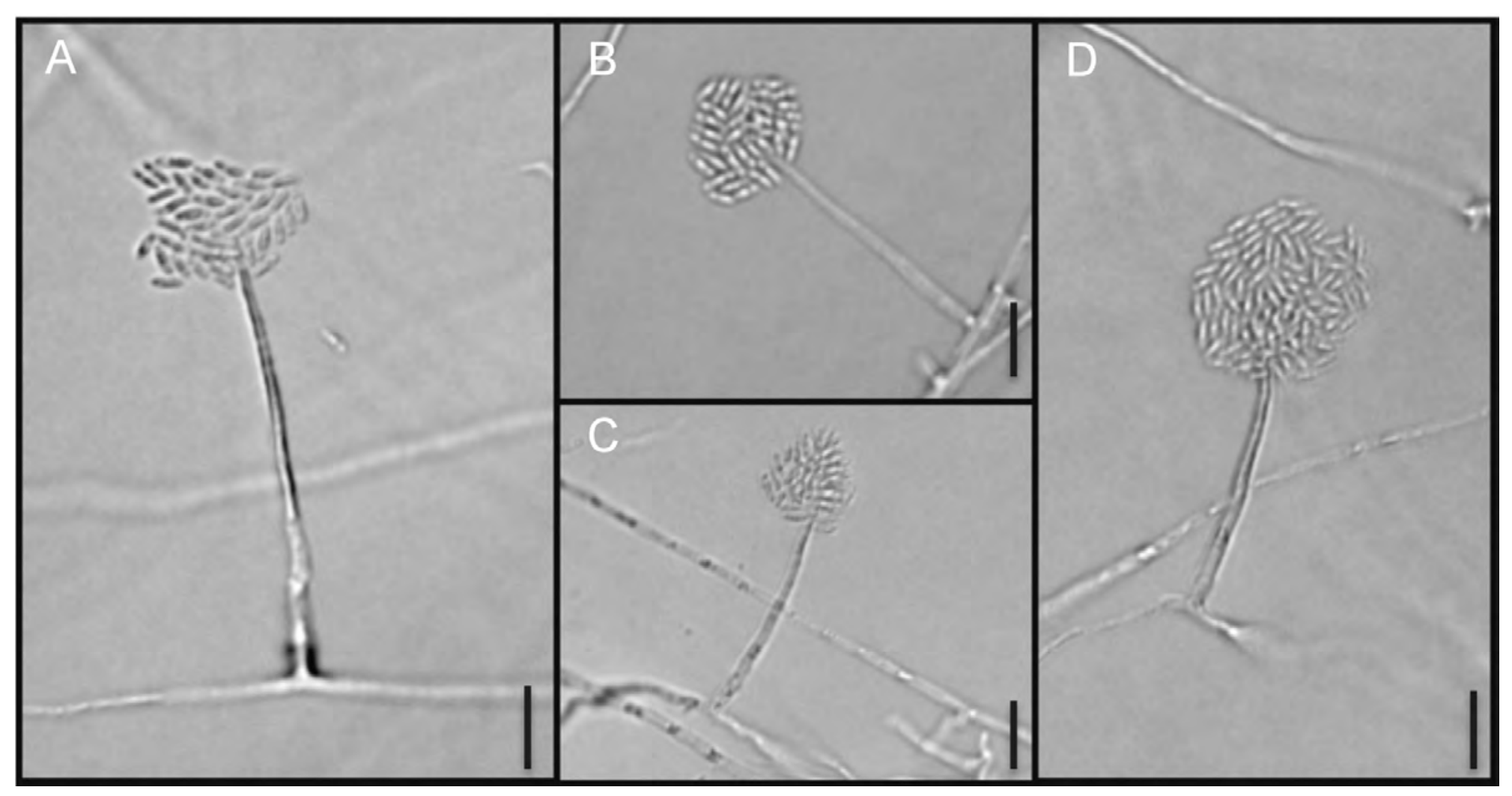




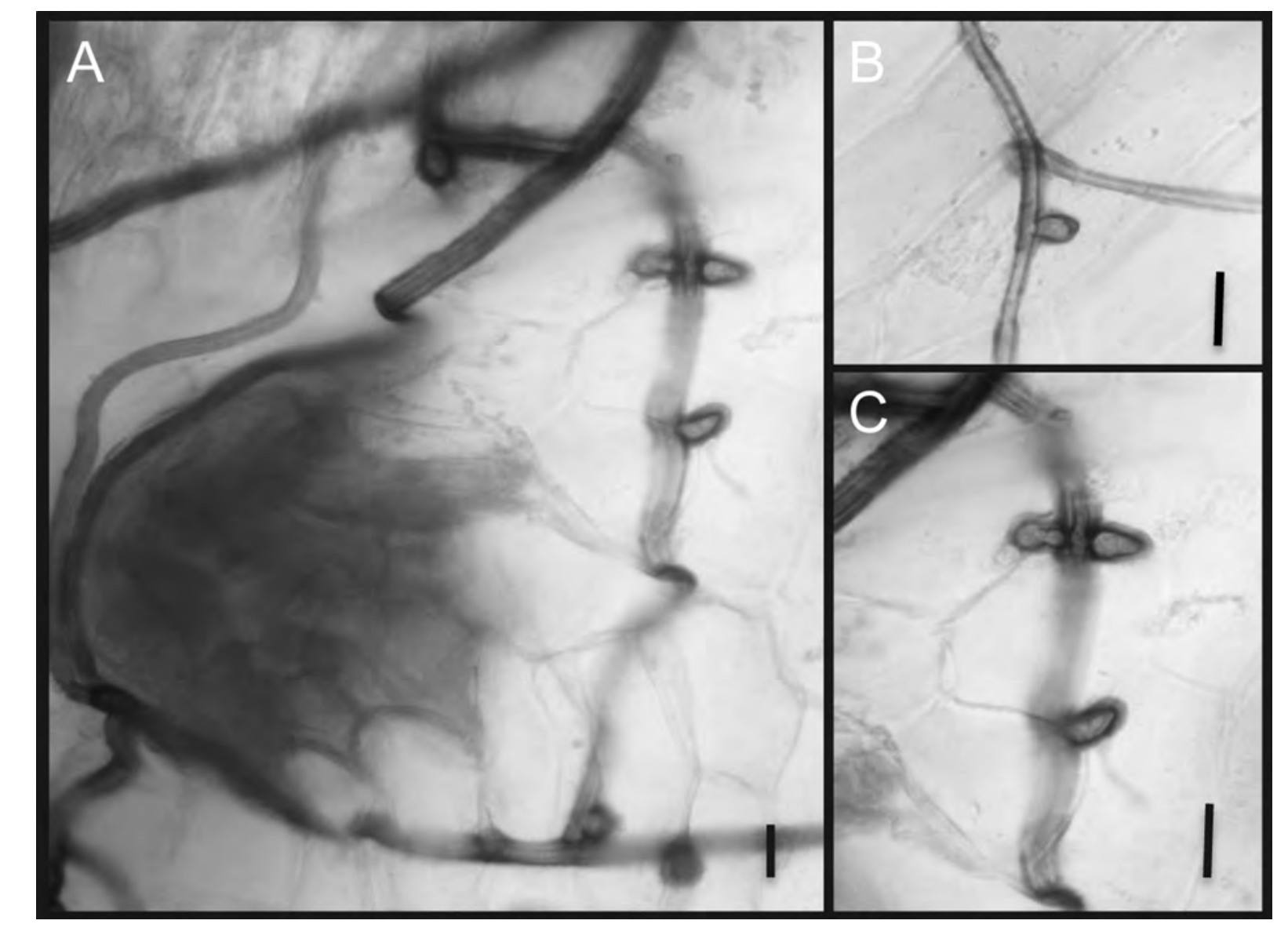

Figure 7

Figure 7

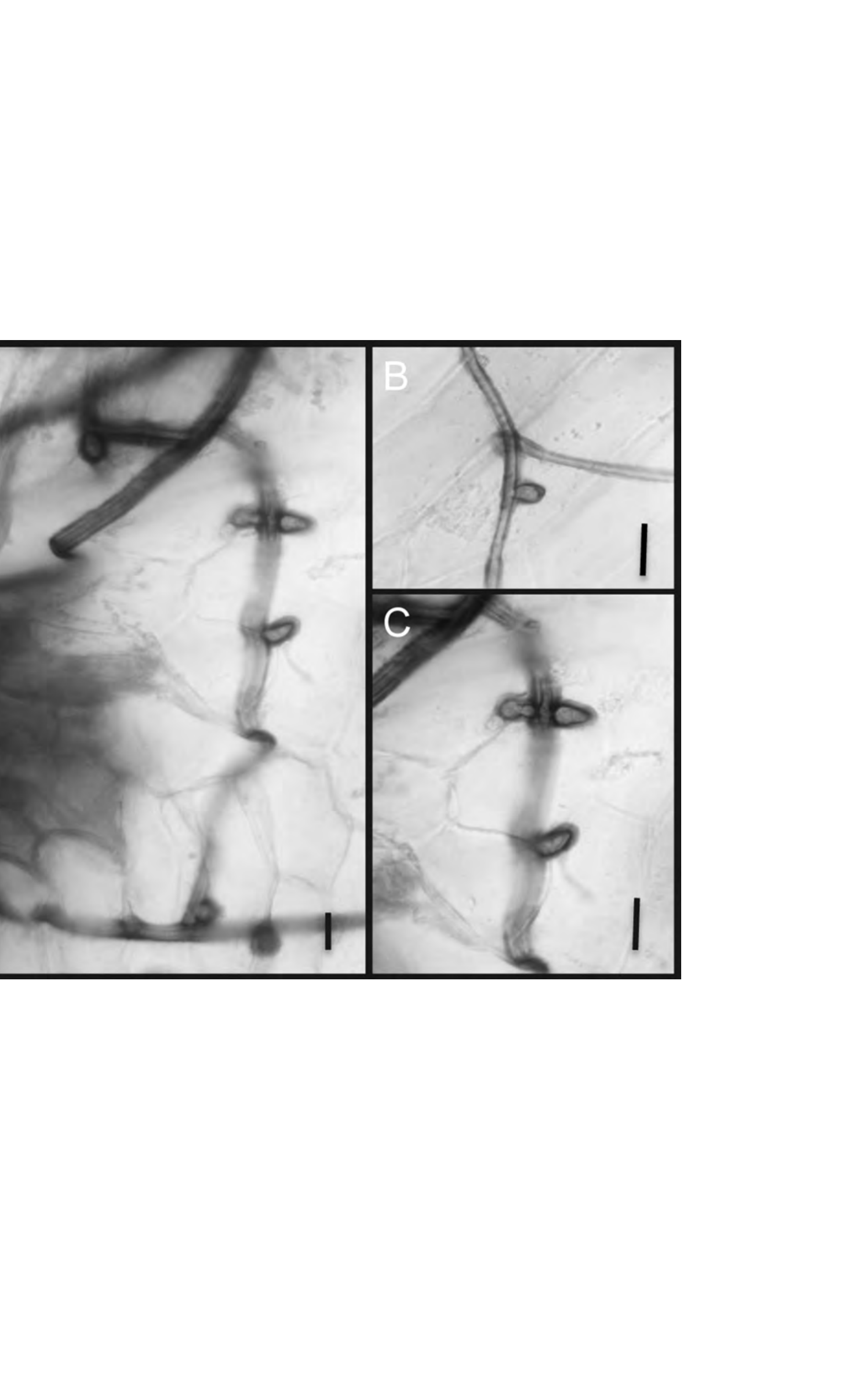

(

